\title{
A study on the occupational challenges and coping strategies of the student athlete coaches
}

\author{
Ju-Young Ryou \& Ok-Seon Lee \\ Seoul National University
}

\begin{abstract}
[Purpose] The purpose of this study was to understand student athletes coaches' occupational challenges from the dual perspectives(social relationship-political system), to analyze the nature of the coping strategies for the challenges, and to provide implications for building a human rights-friendly student athletes club culture. [Methods] Five coaches $(\mathrm{n}=5$, average career length $=19.2$ years $)$ were selected through purposeful sampling. Data were collected by semi-structured interviews with participants. The collected data were inductively analyzed(Patton, 2015). [Results] First, participants struggled with informal roles demanded by the interested parties(principals, athletic directors, parents, and university coaches). Second, the system for protecting student athletes' learning rights, the 52-hour work system and the human rights system added difficulties to the coaches' work environment. Third, the disharmony between interested parties' demands and government agencies' institutional ideals pushed participants to choose anti-institutional, un-ethical, un-educational coping strategies. [Conclusion] The findings suggest that the government, academia and the community should empower coaches as 'the subject of reform' who can solve the problem together rather than regarding them as 'the object of reform.' Furthermore, this conclusion is expected to provide implications to alleviate disharmony between interest parties' demands and government agencies' systems.'
\end{abstract}

Key words: elite student athlete system, coach's occupational challenges, coping strategies.

\section{서 론 \\ 승부조작 몸통은 어딜까. 브로커 대부분은 아마 지도자 (Chosun ilbo, 2016.07.26.). \\ 폭력이 일상이 된 코치... 운동 앞길 망칠라 눈감은 부모들 (Donga ilbo, 2019.02.19.). \\ “그걸 경기라고 했냐" “장난하냐" ( $\cdots$ ) 지도자들 학대 수준 막말 폭언(Donga ilbo, 2019.05.29.).}

논문 투고일 : 2020. 04. 22.

논문 수정일 : 2020. 06. 09.

게재 확정일 : 2020. 07. 02 .

* 교신저자 : 이옥선(okseonlee@snu.ac.kr).
언론매체는 지도자들이 처한 구조적 현실보다 학생선 수의 인권침해, (성)폭력 및 폭언, 부정입시, 승부조작 등 일탈적 사건을 중심으로 보도하며(Entman, 1993; $\mathrm{Kim}, 2010$ ), 경각심을 일깨웠다. 인권친화를 지향하는 정부기관의 정책 또한 지도자들의 행위를 규제하는 예방 적 조처에 가까웠다 $(\mathrm{Lim}, 2014$, p. 196). 학계 내에서도 지도자의 '자질', '역량', ‘전문성'을 보강하고, 전인적 코칭 을 실천하며, 교육자로서의 역할을 수행하길 '기대', '요 청', ‘촉구'하는 목소리가 이어졌다(Choi, 2009; 2012; Jung \& Lee, 2019; Kim et al., 2007; Kim, 2009; Kim, 2011; Lee \& Cho, 2018). 하지만 이러한 노력에도 불구하고 운동부의 비정상적 
현안은 되풀이 되고 있다. 2019년 11월 7일 스포츠인권 특별조사단은 약 10 년 동안 인권보호정책 권고 및 가이 드라인 제정 등 갖은 대책을 시행해왔지만, 여전히 학원 체육의 반인권적 폐단이 재생산되고 있음을 보도하였다. 이미 각 분야의 처방이 상당수 이뤄졌고, 얼마간의 제 도적 장치가 구비된 상태에서도 유사성질의 문제가 재발 한다면, 우리는 기존의 접근에 의문을 제기해보아야 한다.

그동안 언론, 정부, 학계, 사회 전반은 운동부지도자들 이 처한 현실에 진지한 관심을 기울이기보다, 문제의 원 인을 개인(지도자)의 “품성”과 “인권 의식의 부재”로 지목 하고(Tak, 2018, p. 191), 이들을 개선의 대상으로 상정 하지 않았는지 (Lim, 2014, p. 196), 지도자들이 당면한 현장의 딜레마를 뒤로 한 채, 인성교육자로서의 역할이행 을 규범적으로 권고(Ministry of Culture, Sports \& Tourism; MCST, 2019b)해온 것은 아닌지 검토해볼 필 요가 있다.

코칭현장에 내재된 딜레마를 고려치 않고 해소법을 적 용하는 조처는 일선현장의 문제를 해결하기보다 문제를 생산하는 역설적인 결과를 초래하기 때문이다(Jones \& Wallace, 2006, p. 63-64). 코칭 프로세스의 복잡성을 이해하는 작업은 역동적인 코칭환경의 효과적 운영을 위 한 선행요건이며 (p. 51), 그 성패의 중심에는 언제나 코 치와 그들의 실천이 위치해 있었다(Cushion, Armour \& Jones, 2003).

코치의 일이 오케스트라의 지휘로 비유되는 것처럼 (Jones \& Wallace, 2006), 이들은 예측이 어려운 복합 상황 안에서 이해당사자들과 유연하게 상호작용하며 문 제를 조정해야 한다(Jones, Armour \& Potrac, 2002). 또한, 코치는 유·청소년기 선수의 생리적, 정신적, 사회 적 발달의 디딤돌을 제공함으로써, 그들의 잠재력 발현을 조력해야 한다(Stafford, 2011). 특히 국내의 운동부지 도자는 학생선수의 훈련지도, 생활지도, 학교생활 전반 을 조율한다는 점에서 (Kim, 2012), 이들이 운동부 운영 에 어떠한 관점을 가지고 조처를 취하는가의 선택은 향후 선수의 삶에 중대한 영향을 미친다(Seong, Hong \& Choi, 2004).

이와 같이 코치의 일을 이해당사자들과의 사회-문화적 교류로 확장시켜 바라보는 접근은 코칭환경에서 "당연시 여겨지고", “익숙하기에”, "보이지 않았던" 삶의 패턴을 도
출하는데 유용하다(Purdy, 2018, p. 51-66). 특히 '혁 신'을 바라보는 의견이 분분한 과도기적 시점1)에서 운동 부 운영의 핵심주체인 지도자의 눈으로 조직 안팎의 관계 망을 이해하려는 시도는 "인권 친화적 학교운동부 시스템 확립(MCST, 2019b, p. 25)”을 위해 반드시 선행되어야 할 작업이다.

하지만, 그간 학교운동부의 인권에 초점을 둔 연구들 은 학생선수의 학습권 침해(Im et al., 2017; Kim, 2009; Song, Eom \& Shin, 2010; Song, Lee \& Kim, 2013), 성·폭력 및 폭언경험(Jung \& Kim, 2017; Jung, Won \& Lee, 2018; Kang, 2018; Lee \& Im, 2019), 기본권 침해사례 분석 및 고찰(Han, 2014; Hong \& Ryu, 2007; Hwang, 2017; Lee \& Lee, 2013) 등을 중심으로 실시되어온 경향이 있다. 이러한 연구들은 학생선수의 상심을 드러내고, 관련법을 제정하 는데 이바지하였지만, 동시에 운동부 운영의 또 다른 주 체인 지도자의 목소리를 균일히 반영하지 못한 채, 스포 츠인권의 향유대상을 선수 및 가족으로 한정(Jung \& $\mathrm{Oh}, 2015)$ 하는 결과를 만들어내기도 하였다.

구체적으로 말하여, 2006년부터 2016년까지 학술연 구정보서비스(RISS)에 개재된 295편의 학교운동부 관 련 연구 중 '운동부지도자'와 연관된 연구는 20 편 (6\%)에 불과하며, 20 편의 연구마저 '처우개선'과 '선수지도'의 주 제에 편중된 까닭에, 지도자의 직업적 삶을 폭넓게 이해 하는데 한계가 있었다(Jeon \& Shin, 2016).

이후 학교운동부지도자를 주제로 실행된 연구를 살펴 보면, 처우개선(Choi, 2019), 지도전략(Yoon, 2018), 인성교육 실천양상 $(\mathrm{Lim} \&$ Yoon, 2019), 철학으로 해석 한 삶 (Kim \& Park, 2017), 전문성 탐색(Jeong \& Lee, 2019; Lee \& Cho, 2018) 등을 중심으로 지속되어왔다. 이중 Yoon(2018)의 연구는 "변화하는 학원스포츠의 사 회적 현상에 대처하는 고등학교 축구지도자의 지도전략"

1) 2019년 스포츠혁신위원회는 1-7차 권고문을 발표했다. 체육 분야의 대대적 체제개편과 학교운동부의 구조적 혁신을 촉구 했다. 그러나 대한체육회는 <스포츠 혁신위 권고문에 대한 입 장문〉을 통해 혁신위의 권고문이 “현실과 동떨어진" 조처라고 비판했다. 지도자들 또한 "현장 의견이 빠진 스포츠 혁신안, 체육인 무시하는 느낌”이라 평하며 권고안의 재검토를 요청했 다(Yonhap news, 2019. 06.18). 즉 혁신에 대한 정부, 체 육기관, 일선현장의 입장차이가 뚜렷한 실정이다. 
을 탐색하였다는 점에서 주목할 필요가 있다. Yoon은 과 도기적 상황에서 실시되는 지도전략의 양상을 소개하고, 스포츠심리학의 관점에서 그것의 가능성과 한계점에 관 한 유의미한 논점을 제시하였다. 그러나 Yoon이 지칭하 는 “변화”의 범위와 초점 또한 '선수지도'의 국면에 집중되 어있다는 점에서, Jeon \& Shin(2016)이 지적한 “처우개 선'과 '선수지도'로의 편중현상은 여전히 유효해 보인다.

이와 같이 '학교운동부지도자'를 주제로 진행된 연구들 은 '선수지도'에 중점을 두고 제도의 요구에 순응하는 사 례와 필요 ('신뢰와 애정의 관계유지', '민주적 코칭으로의 의식전환, '코칭방식의 변환' 등)를 제시하거나, 일탈의 원인을 고용불안으로 지목하고 이를 위해 “처우개선'이 이 루어져야 함을 역설해온 경향이 있었다(Jeon \& Shin, 2016).

반면, 지도자의 일탈이 결과로 발현되지 않더라도, 꾸 준히 이들을 제도의 역방향으로 종용하는 '압력', 그것이 어떻게 개인들의 선택에 작용하는지를 '일련의 과정'으로 이해하려는 노력은 미흡하였다고 할 수 있다. 따라서 이 러한 제도적 접근의 보충은 지도자들이 당면한 관련 제도 및 정책의 성질을 밝히고, 이들 간의 불협과 모순을 드러 냄으로써, 지속되는 일탈행위의 '궤적'을 추적하는데 유 용한 관점을 제시할 수 있다.

이에 본 연구는 혁신의 과도기에서 운동부지도자들이 마주한 관계적 고충과 함께, 이들이 위험을 감수하면서 제도의 역방향으로 나아가는 연유는 무엇인지, 그 '거역 과 타협의 과정'을 중층(관계-제도)의 관점으로 이해하고 자 하였다.

이를 위해 설정한 구체적 연구문제는 다음과 같다. 첫 째, 운동부지도자는 직업적 이해당사자들과의 관계 안에 서 어떠한 상황을 마주하는가? 둘째, 지도자는 운동부 관 련 제도 및 정책 아래에서 어떠한 변화를 경험하는가? 셋 째, 지도자는 이해당사자들의 관계적 요구와 관련 제도 및 정책의 목적 사이에서 어떠한 성질의 대응을 선택하 는가?

상술된 연구문제의 규명은 학교운동부지도자들이 당 면한 관계적-제도적 환경에 대한 이해를 공유함으로써, 일선현장과 정책입안의 간극 완화에 유효한 시사점을 제 공할 것으로 기대된다.

\section{연구방법}

본 연구는 스포츠혁신의 과도기에서 학교운동부지도 자들이 마주한 직업적 고충과 대응을 탐구의 초점(사례 의 경계)으로 설정한 사례연구이다(Patton, 2015).

\section{연구 참여자}

본 연구의 참여자들은 목적적 표본선정에 기반한 '눈덩 이 표집'으로 선정되었다(Patton, 2015). 이를 위해 연 구자는 풍부한 정보를 가진 최초 참여자로부터 그에 준하 는 또 다른 사례를 추천받았다. 모집과정에 적용된 선별 준거는 첫째, 2 급 전문스포츠지도자(구 경기지도자) 자 격 취득자, 둘째, 10 년 이상의 학교운동부 근무경력 보유 자, 셋째, 5년 이상의 대한체육회 경기실적 보유자였다. 이러한 절차를 거쳐 평균 19.2 년의 경력을 지닌 선수출 신 학교운동부지도자 5 명이 선정되었다.

참여자들의 배경 및 특성은 다음과 같다. 이들은 프로 규모 종목(축구, 농구, 골프 등)이 아닌, 실업규모 종목의 학교운동부에서 근무하고 있다.

오코치는 17 년 경력, 미혼, 초등부 지도자이다. 운동 부 해체 압력에 따른 직업적 소진상태(burn-out)를 겪고 있었다. 정코치는 12 년 경력, 미혼, 중등부 지도자이다. 맡은바 임무에 열정과 책임으로 전념해왔으나, 열악한 환 경과 불투명한 전망에 이직을 고려하고 있었다. 김코치는 23년 경력, 기혼, 고등부 지도자이다. 대회입상 및 대학 진학의 압박에 지쳐있었다. 장코치는 28년 경력, 기혼, 고등부 지도자이다. 변화하는 제도적 방향과 변치 않는 운동부 조직 내외의 요구에 의문을 품고 있었다. 박코치 는 16년 경력, 기혼, 고등부 지도자이다. 학업-운동 병 행, 교육적 코칭, 국가대표 양성 등의 노력을 쏟으며 근무 학교에 헌신해왔음에도 불구하고, 오직 입상 및 진학의 잣대로만 평가되는 처지에 무력감을 느끼고 있었다.

본 연구의 윤리성을 검토한 생명윤리위원회(IRB)의 권고에 따라, 연구자는 특정 정보의 명시가 참여자의 신 원노출로 이어질 위험을 경계했고, 이를 최소화하기 위해 종목정보를 구분치 않고〈Table 1)과 같이 제시하였다. 
Table 1. Characteristics of Research Participants

\begin{tabular}{|c|c|c|c|c|c|c|c|}
\hline & Name & Gender & Marriage & $\begin{array}{l}\text { Length } \\
\text { of career }\end{array}$ & School & Sport & City \\
\hline 1 & Oh & male & not & 17 & elementary & \multirow{5}{*}{$\begin{array}{c}4 \text { disciplines } \\
\text { among } 61 \\
\text { registered in } \\
\text { Korean } \\
\text { Olympic } \\
\text { - Committee }\end{array}$} & \multirow{5}{*}{$\begin{array}{c}\text { Capital } \\
\text { area }\end{array}$} \\
\hline 2 & Jeong & male & not & 12 & middle & & \\
\hline 3 & Park & male & married & 16 & high & & \\
\hline 4 & Kim & male & married & 23 & high & & \\
\hline 5 & Jang & male & married & 28 & high & & \\
\hline
\end{tabular}

\section{자료수집}

본 연구는 다음과 같은 이유로 관찰을 제외하고 면담 을 자료원으로 사용하였다. 첫째, 참여자들의 불안감이 다. 참여자들은 연구문제와 관련된 사례를 제 공하는 행위 가 소속된 조직의 비밀과 불합리함을 누설하는 내부고발 자로 비춰질 수 있음을 걱정하였다. 이러한 참여자들의 반응을 고려할 때, 관찰을 진행하는 것이 어려울 것이라 판단하였다. 둘째, 참여자의 불이익의 위험이다. 설령, 연구자가 집요하게 부탁하여 관찰을 허락받았다고 하더 라도, 관찰하는 연구자의 모습이 특정 인물에게 노출되었 을 때, 그것이 추후 참여자의 피해 및 불이익으로 이어질 위험이 있다고 판단하였다. 셋째, 관찰되기 어려운 사례 의 성질이다. 예를 들어, 참여자들이 반제도적 성질의 행 위 (ex, 대학관계자와의 입시 관련 통화 및 만남 등)를 연 구자가 관찰하는 동안에 노출할 가능성은 희박하다고 판 단하였다.

자료는 2019년 8월부터 2019년 12월까지 반-구조화 된 '면담지침활용법'으로 수집되었다(Patton, 2015). 면 담은 참여자가 편안해 하면서 녹음에 방해되지 않는 지도 자의 숙소 및 사무실에서 1회 2회, 60분 90분 내외로 실시되었다. 연구자는 참여자가 주제와 질문에 대하여 숙 고할 시간을 마련하기 위해 면담 2-3일 전에 면담 가이드 라인을 $\mathrm{SNS}$ 를 통해 전달하였다. 면담 시에는 준비된 가 이드라인을 활용하되, 질문의 순서는 대화의 맥락에 기초 하여 유동적으로 진행되었다.

활용된 면담 가이드라인은 '시간'과 관련된 질문(오전, 오후, 주간, 월, 년, 방학 및 대회출전의 스케줄은 어떻게 전개되는지), '관계'와 관련된 질문(학교장, 감독교사, 동 료지도자, 학부모, 대학감독 등의 대인관계에서 어떤 일
들을 겪어왔는지), '제도 및 정책'과 관련된 질문(학습권 및 인권 보장제, 주 52시간 근무제, 체육특기자제도, 시도 교육청의 정책 등이 직업적 삶에 미치는 영향은 무엇 인지), '대응'방식과 관련된 질문(대인관계와 정책·제도 에서 발생한 모종의 현상에 어떻게 대처하는지)으로 구 성되었다.

\section{자료분석 및 진실성}

본 연구에서 활용한 '귀납적 분석법'은 원자료를 작은 단위로 축약한 뒤, 보다 넓은 패턴(pattern)과 상위 주제 (theme)로 범주화하는 방법이다(Patton, 2015). 이를 위해 연구자는 첫째, 전사자료를 읽으며 연구문제와 관련 되거나 반복적으로 등장하는 부분을 동명사형 키워드로 축약하였다. 둘째, 분류된 키워드들의 연관성을 고려하 며 초기코드를 부여하였다. 셋째, 도출된 하위코드들을 아우르는 현상의 구조를 범주화하였다. 넷째, 범주화된 '주제 내' 및 '주제 간' 코드의 관계(인과, 전후, 대립 등)를 재확인하며 현상 전반을 통섭하는 상위 주제를 도출하였 다. 주제의 경우 현상을 잘 대변하는 참여자의 언어를 찾 아 결과의 부제로 제시하였다. 마지막으로 고충에 대한 참여자들의 대응방법을 동일방식으로 분석하고, 그것을 앞서 확인된 고충의 코딩결과와 비교·대조하며 맥락(고충 -대응)을 유지하였다.

또한, 연구자는 진실성 향상을 위해 분석자 검증법의 일환인 '참여자 검토(participant review)'와 '비판적 동 료 검토(critical friend review)'를 실행하였다(Patton, 2015). 전사 및 해석 자료를 참여자에게 전달한 뒤, 본래 의도와 일치하는지를 확인하였다. 모호한 부분은 참여자 확인 혹은 추가 면담을 통해 파악한 후 괄호 안에 표기하 였다. 동일 전공 박사 학위자 2 명과 연구과정 전반을 공 유하며 해석의 간-주간성을 검토하였다. 나아가, 수집된 참여자의 진술과 관련된 사례의 기사문을 대조하며 현상 의 맥락을 확인하였다.

\section{결과 및 논의}

연구결과는 학교운동부지도자들이 경험한 이해당사자 
들과의 '관계'와 운동부 관련 '제도 및 정책'을 중심으로 제 시된다. 각 절의 후미에는 지도자들이 문제현상에 '대응' 하는 방식의 의미를 분석하여 제시한다.

\section{1. 관계적 고충과 대응: 고군분투}

코칭이 이해당사자들과의 네트워크를 통해 전개되는 복합 활동이듯(Purdy, 2018), 참여자들은 학교장, 감독 교사, 학부모, 대학관계자 및 동료지도자들과 교류하며, 운동부 보존과 직업적 생존을 위해 분투하고 있었다.

학교장: "운동부를 없애려고 움직이시는 분들이 많아요."

각종 민원에 시달리다 교직을 떠나는 관리자들의 소식 이 화두인 요즘, 학교장의 눈에 종종 발생하는 운동부의 사건사고는 언제 터질지 모를 시한폭탄과 같았다. 자칫하 면 소송에 연루되어 경제적 배상까지 책임져야 하는 상황 (KBS news, 2018.07.15.)에서 관리자들은 운영을 꺼릴 수밖에 없었고, 이러한 제약들은 운동부가 “해체”되는 현 상으로 발현되고 있었다.

최근에는 사고도 많이 생기고 미투(me-too), 성추행 이런 게 벌어지다 보니 지금은 운동부를 차라리 안 가지고 있으면 관리자들이 신경 쓸 게 없어, 있는 운동부도 많이 해체되는 그런 상황이 벌어지고 있어(박코치)

교장선생님 같은 경우는 운동부가 없으면 하는 마음이 굉장 히 크세요. 운동부를 없애려고 움직이시는 분들이 많아요. (․) 그런데 명분이 없으니까 명분을 만들려고 하죠. 출전 불가, 선수수급 부족, 시합성적 저조, 이런 거로 없애려고 하시죠(정코치)

학교장은 운영규정강화, 예산부족, 사고위험, 민원부 담 등을 감수하면서 운동부를 유지할 동기를 잃어갔고, 해체를 위한 “명분”을 만들기까지 하였다. 이러한 분위기 아래, 지도자들은 학교장의 계획을 회유하기 위해 그들의 의중을 읽고 요구를 감내해야 했다.

쉬는 시간에 운동장에 나가서 모래를 정리해라? 그건 내 임 무가 아니잖아. 씨름부 지도자도 아닌데 거기서 애들이 놀면 서 다칠 수 있으니까, 안전 지도하고 혹 쓰레기 있으면 줍고 또 쉬는 시간에는 화장실 앞을 지키라고, 학생들이 거기에서 많이 싸운다고. 덩치 큰 코치가 거기에 있으면 애들이 안 싸
우지 않겠냐(웃음), 정말 그만두려고 했어. 이 사람이 나를 간보나? 수도권에 팀이 하나밖에 없고 오래됐으니까, "본인 이 스스로 해체시키기에는 부담이 있으니 코치를 쳐내면 팀 은 자연적으로 없어지겠구나"라고 판단을 해서 나를 집중적 으로 괴롭히나? 그런 생각밖에 안 들었어(오코치)

17 년 경력의 오코치는 “모래 정리”와 “화장실 지킴이” 의 역할요구에 당황했다. 그간 학교에 쏟아온 노력에 대 한 인정은커녕, 굴욕적 대우에 사직까지 고려했다. 학교 장이 전통이 오래된 관할 시·도(市·道) 내 유일의 팀을 해 체시키기엔 부담이 있으니, 지도자인 자신을 내보내어 운 동부를 와해시키려는 속셈이라 의심했다.

또 올해부터 4, 5, 6학년 체육수업(보조)을 맡아. 나한테 일 주일에 10 시간이나 줬어. 그러면 그 10시간 수업을 하는 것 에 따른 보수를 받을 수 있지 않나 물어보니, "당신이 하는 수업은 티칭이 아니라 코칭이다." 그러기 때문에 (보수를) 줄 수 없데. 참, 그래. 주(主)가 내가 되는 건데, 담임선생님 은 다른 일한다고 가버려. 이럴 때 "나는 못 하겠다." "이건 내 업무가 아니다." "내가 왜 체육수업을 하느냐" 할 수 있 겠지만 현실에선 그런 말을 할 수 없지. 속이 뻔히 보이는데 (오코치)

학교장은 명목상 오코치에게 체육수업보조를 요구했 지만, 실상 그것은 무보수 수업지시에 가까웠다. 물론, 오 코치가 체육수업을 맡아야 할 의무는 없다. 그러나 운동 부 해체를 위해 자신의 자발적 사직을 유도하는 교장에게 “이건 내 업무가 아니다"라고 말할 수 없었다.

학교장의 부당대우는 '불합리한 해고'로 나타나기도 하 였다. 박코치는 수차례 우승과 지도자상 수상, 학업 병행 노력을 통한 명문대 진학 등, 제자들의 올바른 성장을 위해 헌신하며 근무학교에 혁혁한 공을 세워왔다. 하지만, 그간 의 노력은 정당히 평가되지 않았다. 공식 매뉴얼 내 평가척 도에는 지도자의 복무태도, 직무수행, 운영성과 등의 항목 이 균일하게 분포되어 있었지만(Seoul Metropolitan of Education: SME, 2019, p. 134), 대회입상은 학교장이 박코치를 평가하는 유일의 척도였다.

교장선생님이 왜 우승을 못 시키냐 이번 대회 우승 못 시키면 그만두게 할 거라는 뒷담을 들었지 ( $\cdots$ ) 내가 얼마나 고생을 한지 직접 눈으로 뵈왔으면서 정말 노력해서 이 아이들을 힘 들게 끌고 왔는데 우승 못 시키면 나를 자른다는 이야기를 들 었을 때, 술자리에서 정말 서러워서 한참을 울었어(박코치) 
박코치의 사례처럼, 한 두 번의 입상실패가 해고로 직 결되는 극단적 경험은 지도자가 승리에 집착하는 주요 동 인이다(Choi, 2019).

참여자들은 학교장의 '운동부 해체'와 '부당 대우'에 대 처하는 방법으로 대회입상을 꼽았다.

우승을 하니까 이야기를 안 하더라고, 교장 선생님이 "박선 생 알아서 해"라고 하셨어(웃음), 성적을 내고 상위권에 있 다 보니까 교장선생님도 교육청이라던지 어떤 다른 기관에 가서 큰소리 칠 수 있게 되고 하니까(박코치)

입상 못하면 구설수에 올라요. 교장부터 동문까지 "그만 둘 때가 됐다. 너무 오래 했다.” 그런 소리가 귀에 다 들리니까. 그럴 때 애들이 한 번씩 우승해주면 싸악 사라지고, 성적 못 내는 지도자는 존재가치가 없으니까요. ( $\cdots$ ) 뭐 학교장이 진 짜 사람이 좋아가지고 "우승보다 더 중요한 것이 있어" 그러 면 몰라도, 지금 우리나라의 어느 학교 지도자들이 성적이 좋은데 잘리겠어요?(김코치)

물론, 대회입상에 의존하는 대응은 " 1 등 만능주의 만연 (Yu, 2005, p, 96)"을 재생산할 위험이 있지만, 이들은 우승 집착이란 퇴보기제를 동원해서라도 운동부의 해체 를 막고 직업적 삶을 연명해야 하는 현실을 마주하고 있 었다.

\section{감독교사: "나 몰라라 하니까요"}

운동부의 원활한 운영을 위해 감독교사의 협력은 필수 적이지만, 가산점 항목이 축소·폐지됨에 따라 교사들이 감독보직을 기피하는 현상이 발생하고 있었다.

감독이면 평일, 주말에 남아서 관리해야 하고 운동 끝날 때 까지 지켜봐야 되고 $(\cdots)$ 자기를 희생해야 하기 때문에 기 피하게 되어 버렸지, 전엔 운동부 하면서 이득도 많았거든 성적을 냈을 때 가산점 이런 것들도 많았는데, 점점 없어지 니까 여가를 없애면서 누가 운동부를 맡으려고 하겠냐고 (박코치)

지도자들은 교사들이 예산, 안전, 출전, 민원 등의 과 중 업무가 자명한데, “이득”보다 “희생”이 많은 고생길을 자청할 이유가 없음에 공감했다. 이어서 당사자의 의지와 관계없이 떠밀려 보직을 맡게 되는 감독교사(Jang \& $\mathrm{Zae}, 2019)$ 의 경우, 담당업무에 “무관심 혹은 책임회피
(Jeon \& Shin, 2016)"의 태도를 보일 공산이 크다는 점 을 아쉬워했다.

시합을 나가야 되는데, 결재를 안 해주고 그걸 "왜 해야 하 냐” 이렇게 필요성을 못 느끼니까 마찰이 많이 생기죠. 시합 을 나가려면 감독의 결재가 있어야 하고 계획을 잡아야 하는 데, 나 몰라라 하니까요. (감독이) 바뀔 때마다 이런 일이 비 일비재해요(정코치)

참여자들은 감독교사가 대회출전을 볼모로 지도자를 쥐락펴락하는 현상(Lee, 2015, p. 28-29)이 비일비재 하다고 진술하였다. 또한 이들은 감독교사의 "빈번한 인 사이동'과 '비협조적 태도'로 야기된 운영의 제한사항을 자신의 해결해야 할 과업으로 인식하고 있었다.

사실 감독님들이 전문가가 아니기 때문에 많은 역할들이 내 게 주어져. 그런데 어떤 사람은 뭐 좀 하려고 하면 "이거 꼭 해야 되냐." 이런 식으로 나오면 방법이 없어. 그래서 학부 모님들이 학교 측에 계속해서 이야기하고 하면 (감독교사의 태도가) 바뀌는데 공립은 또 금방 (보직이) 바뀌어버리는 게 힘이 빠지지(오코치)

참여자들은 '대회출전 방해'와 '운동부 운영 제한'에 대 응하기 위해 인화전략을 활용하고 있었다.

우리 감독선생님이 다른 학교를 갔어, 근데 다른 선생님은 그걸(감독보직을) 안 하겠데 그럼 다른 과목 선생님을 어렵 게 모셔야 해. 선생님 제가 대부분 일을 다 할 테니까요. 운 동부 운영이 될 수 있게 감독직만 좀 수락해주세요(오코치)

운동장 라인 긋고, 천막치고 제가 할 일이 아니어도 앞장서 서 하고, 먼저 공문처리를 하려고 해요. ( ..) 감독님이 미안 하셨는지 더 살갑게 대해주고 뭐 어절 수 없는 상황이니까 그렇게 노력을 하고 있죠(정코치)

참여자들은 감독교사의 마음을 열고 협조를 구하기 위 해 업무를 도맡아 처리했다. 이는 운영의 제한사항을 개 인의 업무스트레스로 치환하는 승자-패자식 대응이었다 (Gitlow \& Mcnary, 2006). 물론, 감독교사와의 인화측 면에서 효과적일 수 있지만, 그에 따른 '업무량 증가'와 '역할의 불분명함'은 코치의 스트레스를 증가시켜 소진상 태(Burn-out)를 초래할 수 있다(Hjälm, 2007). 
처음엔 아이들이 열심히 노력해주는 모습을 보면 보람을 느 겼어. 여기저기 굽실거리면서 해도 애들이 열심히 노력해주 는 모습, 방황했던 애들이 운동을 통해서 달라지는 모습이면 된다고 생각했어. 그런데 아이들한테는 미안하지만 지금은 아무런 동기가 없어(오코치)

또한, 인화전략은 지도자 개인의 직무 관련요인(작업 량, 역할 명료성), 조직 전반요인(보수정도, 승진여부), 직무 환경요인(관리자 스타일, 동료관계)에 영향을 미쳐 '이직의도'를 품게 할 수 있다(Porter \& Steer, 1973).

언제까지 이럴 수는 없는 없잖아요. 저도 요새 정말 고민이 많아요. 다들 지도자에 대한 열정을 가지고 아이들을 가르치 는 것에 희망을 가지고 들어오지만 자기가 생각했던 것보다 너무 많이 열악하고 힘드니까 못 버티고 나가요(정코치)

이상의 분석은 참여자들의 인화전략이 행위당사자의 희생 (직무소진, 이직의도)을 감수해야 하는 전략적 한계 를 지니며, 양자가 공생하는 승자-승자 관계 (Gitlow \& Mcnary, 2006)를 위해, 감독교사의 적극적 참여를 장려 할 방책마련이 필요함을 시사한다.

\section{학부모: "그때만 되면 저는 죽일 놈이 돼요"}

한국의 학부모는 학벌사회의 성공을 위해 모든 자본을 동원해야 한다고 여긴다(Lee, 2008). 이처럼 자식의 진 학을 위한 부모의 열망은 때론 학교에 압력을 넣어 진학 률이 낮은 지도자의 해고를 추진하는 방식으로 표출되기 도 하였다.

우리는 성적을 요새 못 냈는데, 대학 진학을 $90 \%$ 하고 있으 니까 부모님들이 이러쿵저러쿵 안 하는 거고, 다른 학교를 보면 성적은 잘 내는 데, 진학문제로 부모들의 압력에 코치 들이 밀려나는(해고되는) 경우도 있어(박코치)

학교운동부지도자의 공식역할은 훈련지도, 대회출전 및 인솔, 경기력 분석, 안전관리이다(SME, 2020). 하지 만, 문서상의 명시와 달리 현장의 지도자들은 여전히 진 학결과에 따른 책임을 전담하고 있었다.

이들은 대학운동부가 감소되는 상황에서 자신에게 "나 쁜 놈” “죽일 놈” “내 자식 $(\cdots)$ 살려내라”고 쏘아대는 학부 모들의 횡포에 고통받고 있었다.
가장 두려운 것은 부모님들하고 잘 지내다가 대학문제에 대 해서는 꼭 나를 나쁜 사람으로 보는 거, 다른 자식은 가고 내 자식은 못 가는 순간, 부모들은 저에게 원망을 쏟죠. 그 때만 되면 저는 죽일 놈이 돼요. 이제 점점 갈 곳(대학)도 없어지고 지금 많이 지쳐요(김코치)

작년에 두 명이 (대학을) 못 간다고 그랬을 때 부모들이 찾 아와서 내 자식 이제 어떻게 하냐 살려내라고 난리를 쳤지 ( ...) 부담이 돼 매번 힘들고 스트레스가 엄청나 심리적으로 고통스러워(박코치)

이 중 박코치는 학부모의 진학 압력에서 벗어나기 위 해 2 가지 전략을 동원하였다. 첫째는 공식절차를 거친 '학교발전기금(SME, 2019; 2020)'을 근절함으로써 추 후 학부모 민원의 근거를 차단하는 것이었고, 둘째는 상 급학교와의 진학 협상을 위해 자신이 동분서주하고 있음 을 부모에게 알려 트러블을 방지하는 것이었다.

학부모에게 발전기금을 받아서 학교에서 다시 코치에게 월 급을 줄 수 있지만은 그렇게 부모님들에게 받아가지고 코 치 선생님 월급을 준다고 했을 때, 나중에 애들이 진학 못 했을 때, 감정이 생길까 봐 아예 차단하고 떳떳하게 $(\cdots)$ 부모님에게 받는 것은 일절 없고, 부모도 우리에게 그런 것 을 이야기하지 못하게 사전에 차단하려고 노력을 하고 있 지(박코치)

3학년 때 트러블이 있을 수밖에 없다고. 그 트러블을 없애기 위해서 내가 발로 뛰고 모든 대학에 전화해서 알아보고 있 다. 이 과정을 항상 오픈시켜, 부모들한테 애가 대학 갈 실 력이 안 되는데 전화를 해서 노력하고 알아보고 있습니다. (...) 이렇게 상황을 말씀드립니다. 조금 더 시간을 두고 지 켜봐 주세요. 이렇게(박코치)

첫 번째 대응은 학부모의 경제자본(후원금)과 지도자 의 사회자본(진학매개능력)의 거래를 끊음으로써 학부모 의 불만을 봉쇄하는 조처였다. 이는 부모와의 관계적 고 충을 완화할 수 있으나, 본봉 170만원(Choi, 2019, p. 66)의 생활고를 감내해야 지속 가능한 전략이었다.

두 번째 전략 또한 학부모-지도자 갈등을 임시적으로 해소할 수 있지만, 대학 관계자와의 관계망을 유지해야 한다는 점에서 한계가 있다. 그의 대응은 이어지는 오코 치의 진술처럼, 고교 지도자의 “읍소”와 대학 관계자의 요 청을 빙자한 혼탁한 거래(불법청탁-우수선수 요구)로 변 질될 위험을 내포하고 있었다. 
부모님들은 대학 못 가는 건 코칭스태프의 능력 때문이라 생 각하니까 (..) 애가 잘해봐 그럼 대학에서 먼저 보내 달라고 그러지, 애가 (실력이) 안 되니까 맨날 고등학교 코치들이 대학 가서 읍소하고 어떻게 좀 잘 좀 부탁드립니다. 계속 그 런 상황이지(오코치)

이상의 현상은 운동부 안팎의 “갑질”의 행위주체를 지도 자로 가정하는 선입견의 재생(Chung cheong namdo Office of Education; COE, 2020, p. 60-61)을 자제하 고, 권리보호의 의무자를 특정 개인(지도자)이 아닌 구성 원 전체로 재설정해야 함(Jung \& Oh, 2015)을 시사한다.

대학 감독·동료 지도자: "이미 짜여진 판이 있으니까" 정부기관은 부정입시를 타파하기 위해 다방면의 노력 을 기울여왔지만, 일선현장에서는 여전히 학연, 지연, 혈 연으로 이어진 암거래가 성행하고 있었다.

문이 좁고 한 다리만 거쳐도 선배, 후배, 스승, 제자, 이런 학연, 지연에 얽혀있고 한 다리 건너 가지고 누구의 뭐뭐 얽 히고설킨 부분들이 많아서 대학 관계자들, 감독, 코치, 그 (관련된) 사람들이 가게 될 수밖에 없는 상황이거든(박코치)

이와 같이 지도자들이 사전스카우트가 현행 제도와 규 정(Korea University Sport Federation, 2020)에 반하 는 행위임을 주지하면서도, 동조할 수밖에 없는 연유는 대 입 정책의 절차적 공정성이 상실된 채, “짜여진 판”에 따라 진학이 결정되는 현실에 놓여있기 때문이었다(Joongang ilbo, 2020.01.08; JTBC News, 2018.11.20).

대학 보내는 것도 정책적으로 수시 원서를 모두 누구나 집어 넣게 되어있지만, 제도적으로는 그렇지만 그렇지 못한 부분 이 그 대학 감독과의 관계 때문에 우리가 원서를 넣고 싶어 도 못 넣는 상황이 많지. 이미 짜여진 판이 있으니까(박코 치)

이어서 박코치는 동료지도자들과 경쟁하여 한정된 진 학 자리를 꿰차기 위해 “비밀리에 (관련)정보를 입수하고 작전”을 구사하는 경우가 다반사라 첨언하였다. 또한 그 는 다른 팀 지도자의 술수에 속아 제자를 낮은 등급의 대 학에 진학시킨 경험에 빗대어 진학 첩보전의 구체적 양상 을 묘사하였다.
아는 지도자가 먼저 전화가 와서 "우리 애 이렇게 해서 00 대학을 가기로 했다" 고 결정을 딱 내려버리더라고, 그 대학 하고 나하고 이야기한 것이랑 달라서 의아했는데, "벌써 끝 났다"고 해서 거길 못 보낸 적이 있어, 그런데 나중에 보니 까 개가 이야기를 끝낸 것처럼 나한테 (거짓말로) 이야기를 한 거야. 끝난 게 아니었는데 끝난 것처럼 이야기해서 나는 우리 애를 (등급이 낮은) 딴 쪽으로 보냈는데(박코치)

박코치는 진학 첩보전의 패배를 되풀이하지 않기 위해 보다 치밀한 전략을 강구하였다.

$0 \bigcirc$ 대학에서 우리 선수 2 명을 이야기를 해서 시합도 뛰고 하다가 그 대학교가 신빙성이 떨어지는 것 같아. 그럼 다른 대학하고 이야기를 하지. 그래서 이 대학교 아니면 다음에 그 대학을 보내려고 2 3개 대학을 걸쳐놓는 거야. 여기 대학 이 안 되면 그다음 순위의 대학으로 보내면 되니까(박코치).

박코치의 후기대응은 '문어발식 연결망'을 구성하여 진 학의 안전판을 확보하는 것이었다. 이러한 대응은 '사전 연락'을 취하던 초기대응보다 높은 안정성을 담보하였지 만, 동시에 이는 대학관계자들과의 네트워크를 확장해야 한다는 점에서 연고주의적 부정입시의 관행(Jung \& Choi, 2010)을 심화시키는 자충수이기도 했다.

\section{2. 제도적 고충과 대응: 설상가상}

학원체육의 정상화를 지향하는 제도 및 정책(학습권 보장제, 주 52 시간 근무제, 인권 보장제)의 결은 아이러 니하게도, 지도자들로 하여금 반제도적, 비윤리적, 비교 육적 대응을 택하도록 종용하고 있었다.

\section{학습권 보장제: "목이 조여 오는 거예요"}

학교체육진흥법 제 11 조(학교운동부 운영 등)에 따르 면 학습권 보장제는 제도적 조처를 통해 학생선수의 학습 권리를 보호하려는 국가단위의 노력이다. 지도자들은 학 습권 보장제의 필요성에 절감하면서도, 훈련환경에 제약 을 가하는 상황을 마냥 달갑게 받아들일 수 없었다.

(정규수업 받고) 4시에 나와서 운동하는데 썬크림 바르고 뮈하고 꾸물거리면서 체조하면, 목소리를 높일 수밖에 없어 요. 직장에서 살아남으려면 어쩔 수 없이 입상을 해야 되고 대학을 보내야 하는데, 이게 시간은 점점 줄어드니까 목이 조여 오는 거예요. 그러니 애들한테 화를 내고(김코치) 
하지만 “목이 조여 오는” 불안감의 주요원천은 훈련시 간의 감축이 아니었다. 그것은 제도가 전국단위에서 동일 하게 적용되지 않는다는 인식에서 비롯되고 있었다.

국가적인 차원에서 이 제도적인 것을 16 개, 17 개 시 · 도에 서 전부 정규수업을 이수하라고 지침이 내려오고 하지만, 말했듯이 수도권에서는 $100 \%$ 지켜지는 것 같고 아직 지방 은 아니야 ( $\cdots$ 실질적으로 현재 이루어지지 않는 학교들도 암암리에 있는 것으로 알고 있는데(박코치)

모 시 · 도에 있는 모 학교 지도자가 나한테 이렇게 한다고 말 했어. 자기 선수들은 체조 대형으로 밥을 먹고 그 자리에 바 로 누워서 잠을 자고 신발 끈을 묶고 바로 체조하고 운동을 한다는 거야. 그건 뭐냐 경쟁이 안 된다는 거지 그 학생들이 전국대회 성적은 수십 번씩 내는데 $(\cdots)$ 아직은 지방에서는 애들 수업보다는 운동이 우선인 곳이 많으니까. 아까 000 시 · 도 형님네 도 그렇고. 시합 나가서 애기 듣고 하다 보면, 다 알게 되지 "아... 수도권처럼 철저하지는 않구나”(오코치)

이미 국가수준에서 주중 훈련시간에 대한 규정을 마련 할 것을 권고(MCST, 2019b)했음에도 불구하고, 시·도 교육청의 공식문서 내용과 관리·감독의 차이가 두드러지 는 정황들2)은 어쩌면 참여자들의 불안처럼, 시·도마다 학습권 보장제의 강제성이 상이하게 적용되고 있음을 방 증하는 증거일 수 있다.

참여자들은 훈련시간의 차이를 극복하기 위해 2 가지 전략을 활용하였다. 첫째는 수업 이외의 시간을 훈련으로 보강하는 것이었다.

4시 수업 끝나고 2시간 남짓 운동을 하는데 턱없이 부족해. 토요일하고 일요일, 연휴기간 공휴일 이럴 때, 대체로 하고 있어 새벽에 하고 싶었는데 인문계는 수업을 일찍 시작하니 까, 진행이 어렵고 주말을 많이 이용하지(박코치)

방과 후, 방학 때 최대한 많이 뭐 하루에 3번 정도 운동을 한다고 생각을 하고, (애들이) 힘들긴 하죠. 그래도 할 시간 이 없으니까 겨울방학 때 노력을 많이 하죠(정코치)

2) 일례로 서울시교육청은 2020년부터 초등 2.5 시간, 중등 3.5 시간, 고등 4.5 시간으로 훈련시간을 제한할 것을 권장하였고, 2021년부터 의무이행을 명시하였다(SME, 2020). 하지만 충남의 경우 ‘훈련시간제한'에 대한 내용이 언급되지 않고 있 다(COE, 2020). 또한 $\operatorname{Sun}(2019)$ 은 G광역시에서 시합 전 단위학교별 학습권 보장이 달리 이행되고 있음을 보고한 바 있다.
이와 같은 대응은 물리적인 방식으로 훈련시간을 보충 할 수 있지만, 빠듯한 학업-운동의 병행으로 선수의 피로 를 가중시켜 수업시간에 졸게 만들 수 있다(Kim, 2011). 나아가 학년이 올라갈수록 어려워지는 수업내용에 스트 레스를 받고 자신감이 감소되는 악순환(Kim, 2015)에 빠트릴 위험이 있다.

두 번째 대응은 진학이 급한 고학년에게 올인하기였다.

아무리 단체운동이래도 1학년들보다 3학년에게 쏟는 시간 이 많아지고요. 예전 같으면 전체적으로 봤다면 요즘은 급한 애들만으로 벅차니까요(김코치)

일단은 할 수 있는 걸 먼저 해야지 기본기보다는 시합에서의 전략적인 것들, 그리고 3 학년에 집중을 하지, 이 애들은 당 장 대학을 가야 되니까. 이게 매년 반복되는 게 좀 그렇지 (박코치)

물론, 올인전략은 저학년 및 이외의 선수를 방관할 위 험을 동반한다. 코치의 차별을 경험한 선수는 체육관과 교실, 어느 곳에서도 발을 붙이지 못한 채 소외를 경험할 수 있다(Kim \& Cho, 2004). 나아가 지도자의 관심부족 및 출전기회의 제한은 선수의 중도탈락으로 이어지는 원 인을 제공했고(Barnett, Smoll, \& Smith, 1992), 그것 은 다시금 지도자를 윤리적 갈등으로 빠트렸다.

"저도 그만두고 싶습니다. 대학교도 못 갈 것 같고." 이런 아 이들, 진짜 몇몇 아이들은 신체조건이 안 좋고 앞으로 어떻 게 될지 모르겠지만, 옛날 같으면 며칠 쉬고 생각해봐라, 쉬 다 돌아와 언제든지 받아줄 게 공부 좀 해봐. 그랬는데 지금 은 이 아이가 그만두면 (인원 부족으로) 시합을 못 나가니까 다른 열심히 하는 아이들한테 피해를 주잖아요. 그러다 보니 다시 운동을 해라 너 충분히 (대학) 갈 수 있다. 그런 솔직하 지 못한 말도 하는 제 자신이 하...(한숨) 밉고(김코치)

따지고 보면 애들이 무슨 죄가 있겠어, 말썽 안 피고 열심히 노력한 애들밖에 없는데, 애 (대학 갈) 능력은 안 되고, 나는 보내 줘야 하고 그럴 때가 가장 힘들어 올해도 벌써 그런 상 황이 벌어지고 있고(박코치)

지도자들은 비우수 선수의 중도탈락과 장래, 대회출전 의 고민으로 골머리를 않았다. 이러한 윤리적 번민의 깊 이는 곧 자신의 전략으로 소외된 선수에 대한 죄책감을 부정입시(우수선수사이에 끼워 진학시키기)로 합리화 
(Bing \& Jang, 2010)할 유혹에 노출된 정도를 의미하는 것이기도 했다.

\section{주 52시간 근무제: "이름만 올려놓고"}

운동부 운영에 적신호가 켜졌다. 지도자는 대회출전 및 전지훈련 등의 스케줄을 소화해야 하지만, 감축된 근 무시간으로는 어려웠다. 관리자는 감독교사가 자청하지 않는 이상, 지도자의 근무시간 외에 발생할지 모를 사고 위험을 감수하며 출전을 감행할 이유가 적었다(Yonhap news, 2019. 10.31). 역설적이게도, 근무환경의 개선을 위해 시행된 '주 52시간 근무제'는 오히려 지도자들의 근 무환경에 제약을 가하고 있었다.

대회 나가고 전지훈련 가서 애들 관리하는 게 아무것도 아닌 일이 아니잖아, 무조건 넘지 시합 나가면 (기존) 68시간도 사실은 모자란 건데 덜 버는 걸 감안해서 나가지. 그거 자체 를 못 나가게 빠꾸(불허) 거는 게 진짜 문제지(오코치)

지도자들은 일한 만큼 보상받지 못하는 것도 문제지 만, “진짜 문제”는 관리자들이 대회출전을 불허 (“빠꾸”)하 는 것으로 인식하였다.

고무적인 것은 관리자가 지도자의 직무특성을 고려하 여 외근 시 소정의 근로시간을 인정하거나, 근무시간의 증 감을 통한 유연한 운영 방식이 적용될 수 있음을 명시하는 곳이 생겨나고 있다는 점이다(Busan Metropolitan of Education; BME, 2019; SME, 2020). 하지만, 이러한 문서상의 개선에도 불구하고 지도자들이 주 52 시간 근무 제를 바라보는 시선은 여전히 냉소적이었다.

일찍이 매뉴얼에 명시되어온 바와 같이 지도자의 직무 특성을 반영한 '유연 혹은 탄력 근무제 (SME, 2017, 2018, 2019)'를 운용하면, '대회출전의 관리·감독 문제' 와 '지도자의 근로복지 문제'를 해결할 수 있지만, 이제까 지 근무학교가 행정상 편의에 초점을 두고 기존경로를 고 수해온 까닭에, 52 시간제에 따른 '출전제한'의 문제가 발 생한다는 것이었다.

이게 문제가 뭐냐면, 52 시간을 해라, 그러면 학교에서는 10 시에 출근해서 7시에 퇴근하는 똑같은 방향으로 하려고 해, 옛날부터 진짜 이런 유연 근무방식을 많이 하라고 말했는데, 내가 볼 때 진짜 유연근무제를 잘 이용하면 좋은데, 학교가 그냥 출근을 시켜버리고 (지도자가) 자리에 앉아있는 걸 원
한단 말이야. 그게 행정적으로 더 편하고 관리자 입장에서 문제가 없으니까 ( ...) 대회가 없을 때 한 달 또는 몇 주 전부 터 근무시간을 줄여서, 시합 때 모자란 부분을 쓰면 충분히 (대회) 싸이클을 맞출 수 있거든 근데 그게 아니니까 말이 많은 거야(오코치)

탄력 근무가 있다고는 하는데 학교에서 그렇게 연연하지는 않는 것 같아요(정코치)

이상의 현상은 경로 의존성(path dependency in policy)이 발현된 것으로 해석될 수 있다. 제도의 변동은 내·외부적인 환경 변수들이 관련된 개인들에게 영향을 미 쳐 새로운 변화로의 동참을 이끌어내지만, 그렇지 않을 경우, 설령 기존의 제도가 비효율적일지라도 그 경로를 유지하려 한다(James, Bryan \& Frank, 2019). 기존 경로에 누적되어온 “선호, 이해, 아이디어, 루틴, 집단 정 체성 등의 요인(Tak, 2018, p. 177)"이 특정 개인으로 하여금 새로운 제도를 선택하는 폭을 한정하기 때문이다 (Kay, 2005). 즉 관리자의 입장에서 선택사항인 유연근 무를 위해 모종의 비용을 지불하면서까지 기존의 (운영) 경로를 전환해야할 이유가 적었다.

이처럼 유연근무가 운용되지 않는 상황에서 오코치가 '출전제한'에 대응하는 방식은 교사에게 결제라인에 이름 만 올려 달라고 부탁하는 것이었다.

선생님한테 부탁을 해야 돼. "선생님 제가 다 알아서 할 테 니까 이름만 올려놓고, 시합 때 벤치에만 앉아주세요" 결재 할 때만 선생님 이름을 올리는 거야, 운영을 하기 위해서는 그렇게 될 수밖에 없는 거지, 팀이 있어야 코치가 있는 거니 까. 진짜 책임감 있는 감독님이 아니고서야 시합 나가면 코 치가 (아이들을) 다 보게 되지 결국(오코치)

오코치의 대응은 52 시간 근무제를 위반하는 반제도적 행위임은 물론, 업무량에 비해 보수가 적다는 인식을 품 게 함으로써 직무동기를 저하시킬 수 있다(Lee, 1989). 하지만, 대회출전이 곧 운동부 존폐 및 직업적 생계와 직결 되는 현실아래, 그에게 주어진 이외의 선택지는 없었다.

상술된 현상은 각 시·도 교육청이 주 52 시간 근무제의 본래 시행 목적인 근무환경개선을 위해, 유연한 근무운용 의 구체적 기준과 사례 $(\mathrm{BME}, 2019, \mathrm{p} .35-37)$ 를 공유 함으로써, 추후 고용자(관리자)와 피고용자(지도자)의 '근로시간 산정 및 운용방식 협의'를 건설적인 방향으로 
이끌어갈 필요가 있음을 시사한다.

\section{인권 보장제: "우리는 잠재적 범죄자니까"}

인권보장 관련 정책 및 교육은 학생선수의 권리보호에 공헌하였지만, 동시에 지도자들이 이행해야 할 '인성교육 자로서의 역할(MCST, 2019b)'을 제한하며 현장의 혼란 을 가중시키고 있었다.

“뭐 선생님이? 그럼 신고해” 이렇게 돼버리니까 (...) 단지 아이들이 많이 달라져 가지고 선후배가 없다는 것, 이기적 이라는 것, 이런 상황에서 껄렁한 애들을 다루는 것이 불가 능하고 그런 애들은 현재 상황을 이용하고 있다고 봐요(김 코치)

코치 선생님들은 우리를 혼낼 수 없다는 것을 알기 때문에, 지도자의 심리를 가지고 악용하는 애들이 있지. 이런 상황을 이용하는 아이들이 많아(박코치)

요즘 애들은 솔직히 나도 겁나. 법적으로 휘말리니까 실제로 내 친구가 그렇게 되었고, 화장실에서 선생님을 욕하는 걸 들어도 그걸 보고도 뭐라고 쉽게 못 하는 거야(오코치)

참여자들은 학교운동부지도자를 부정적으로 바라보는 사회적 편견과 선수의 인권을 강조하는 현행 정책의 경향 아래에서 인권을 "악용”하는 "껄렁한" “요즘" 선수를 다루 는 일이 불가능하다고 인식하였다. 여차하면 영구제명 (SME, 2020) 혹은 법적 소송으로 이어지는 상황에서 인 성교육은 언감생심이라는 것이었다.

유사한 맥락에서 Song \& Lee(2015, p. 35, 39) 또한 학생선수들이 “불리하거나 지도자가 마음에 들지 않을 때” 이전의 신체접촉을 수반한 동작교정을 악용하는 사례 를 제시한 바 있는데, 이러한 현상이 발현한 이유는 선수 들의 인권침해가 사회의 주요문제로 공론화되면서 인권 보장의 대상이 선수로 집중되었기 때문으로 해석된다 (Kim \& Kim. 2019, p. 39), 즉 현행 인권보장 정책 및 교육은 선수의 권리를 보호하는데 역점을 둔 나머지, 지 도자 또한 이해당사자들과의 관계 안팎에서 권리를 침해 당할 수 있음(Jung \& Oh, 2015, p. 38)을 간과하고 있 다. 일례로 국가인권위원회가 2017년부터 제공해온 〈스 포츠인권 표준 교안>을 살펴보면 운동부지도자를 '혁신의 주체'가 아닌 '혁신의 대상'으로 설정하고 있음을 파악할
수 있다. ${ }^{3)}$

이러한 관점으로 전개되는 인권교육은 스포츠인권의 향유대상을 선수로 한정하고, 지도자가 피해자일 경우를 생략함으로써, 지도자는 곧 가해자란 이해당사자들의 선 입견을 강화할 위험이 있다.

인권 쪽에서는 매번 연수가 온단 말야 ( $(\cdots)$ 완전히 코치 선 생님들을 잠재적 범죄자로 보고 이렇게 하면 형벌 몇 년이고 이렇게 하면 안 된다. 심지어 (연수)자료도 코치 영구제명, 지도자 자격금지, 이런 식으로 나오니까. 애들 인권을 지켜 줘라 그것도 좋지만, 계속 그런 내용만 나오는 거야. 자기들 은 거기서 판단만 하는 거야. 지도자를 어디서도 배려하지 않아 우리는 잠재적 범죄자니까, 몰라 처음에는 (지도자들 을) 겁을 먹여서 도움이 될 수 있겠지 근데 이미 코치 교육 을 몇 년 받은 사람, 계속 코치 생활을 해나갈 사람들을 위해 서라면 진짜 인권에 대해 알려줘야 한다고 생각해(오코치)

자주 그런 교육해요 학생인권을 지켜라. 그런데 지도자 인권 은 없어요. 코치의 인권은 여기서 아무것도 없어요(김코치)

참여자들은 지도자를 “잠재적 범죄자”로 간주하고 "영 구제명”, “자격금지”, “형벌”을 공지하듯이 전개되는 인권 연수의 교육방식에 문제를 제기하였다. 유사한 맥락에서 $\operatorname{An}(2019$, p. 66) 또한 “무분별한 인권교육은 개인의 지 나친 권리주장과 더불어 머릿속에 고소, 고발이라는 인식 을 남기게 됨"을 지적하고, 대한체육회 및 대한장애인체 육회 등의 기관 인권교육에 의문을 제기한 바 있다. 이러 한 정황들은 그간 정부 및 공공기관의 인권보장 정책과 연수가 당위적인 방식으로 인성교육자로서의 역할을 권 고해온데 비해, 그러한 환경을 마련하고 방안을 강구하는

3) 〈스포츠인권 표준 교안〉은 '피해자로서의 학생선수'와 '가해자 로서의 지도자'를 암시하는, 다소 한정된 논리로 전개되는 경 향을 보인다. 목차를 제외한 약 60 페이지의 내용 중 학생선수 관련 내용은 기본적 인권, 권리보호, 고립, 학습권 부재, 정체 성 및 자긍심 훼손, 의욕상실, 신체적 손상, 정신적 피해, 대처 방안 숙지, 예방정책접근 권리, 강요받지 않을 권리, 행복추구 권리, 학생-선수로서의 자율권 보장, 존엄한 인격체, 인간적 존엄, 인격적 존중, 전인적 성장 등 '권리와 보호'의 키워드 $(p$. $10,13,23,30,33,41,46,53,65$ )와 주로 연결된다. 반 면, 지도자의 경우 (성)폭력, 횡포, 분노, 힘의 과시, 체벌, 단 체기합, 폭력용인, 퇴출강요, 출전권 이용 협박, 과도한 훈련 강요, 욕설, 모욕감 제공, 명예훼손, 성차별, 권위주의, 성(性) 길들이기, 성적 농담, 자격 없음, 사적 만남 및 데이트 강요, 폭력 이미지 등 '가해 및 범죄'의 키워드(p. 14, $17,18,19$, $22,27,31,32,38,39,42,43,52)$ 와 연관되고 있음을 확인할 수 있다. 
데에는 관심이 미약했음을 대변한다.

가장 기억에 남는 연수인데, "애들이 너무 말 안 듣고 힘들게 하면, 밖에 나가서 그냥 담배 한 대 피면서, 재들은 그냥 어 디가 아픈 애들이다" 이렇게 생각하라는 거야(웃음) (오코치)

지금은 다하지 말고 다 안 된다고 하니까 작년에 애가 하나 그만뒀는데 개가 지금은 건달을 한대요. 문신은 온몸에 두르 고 (학교) 안에 있는 애들하고 접촉을 하니까 그걸 어떻게 놔두냐고, 애들 미래를 생각해주는 게 아니라 아무 대책 없 이 하지 말고 안 된다고만 하니까요(장코치)

정부 및 공공기관을 포함한 사회 전반이 지도자를 “잠 재적” 가해자로 추정하고 규제하는 상황에서 참여자들이 취한 현실적 대응은 방임이란 비교육적 조처였다.

애가 좀 더 발전할 수 있는 사항들을 지도자들이 그냥 넘어 가 버리는 게 아닌가. 예전에는 더 이렇게 해서 가르치려고 했지만 요즘에는 괜히 내가 힘든 일 겪지 않을까? 애들을 가 르치기 위해서라기보다 조금은(정코치)

또한, 참여자들은 요즘 선수들을 다루는데 기존방식 이외의 대책을 모색하지 못한 채 어려움을 호소하였는데, 이는 변화된 선수들의 특성을 고려한 '인성교육의 구체적 인 내용과 방법(Lim \& Yoon, 2019)'에 관한 대안적 페 다고지가 미흡한 상태임을 암시한다.

상술된 현상을 종합할 때, 현행 인권 보장제는 외부변 인(불균형적 인권교육)과 내부동인(지도자의 대안적 페 다고지의 부재)이 결합되어, 이해당사자들의 '인권오용' 과 지도자의 '지도방임'을 일관하게 만들 여지가 있다.

\section{요약 및 제언}

본 연구의 목적은 혁신의 과도기를 마주한 학교운동부 지도자들이 '관계'와 '제도'의 측면에서 어떠한 변화를 경 험하는지 이해하고, 그러한 고충에 대응하는 방식을 분석 하는 것이었다.

참여자들의 고충은 변함없는 이해당사자들의 요구와 급변하는 혁신 제도 간의 괴리에서 초래되고 있었다. 이 들의 대응은 고충을 근본적으로 해결할 수 없는 임시방편
적 성격을 띠고 있었으며, 학원체육의 구조적 폐단을 재 생산할 위험을 내장하고 있었다. 앞서 확인된 연구결과를 바탕으로 제언을 제시하면 다음과 같다.

첫째, 지도자의 역할갈등은 '개인의 욕구(need)'에서 나아가 '이해당사자들 간의 욕구(inter-needs)'로 확장되 어 논의(Coulter, et, al, 2016)될 필요가 있다. 기존의 연구는 비정상적 현안의 원인을 운동부지도자들의 고용 불안으로 지목하고, 이를 위해 '처우개선'이 이루어져야 함을 강조해온 경향이 있다. 그러나 본 연구의 결과에 따 르면 지도자들의 반제도적, 비윤리적, 비교육적 대응은 학교장, 감독교사, 학부모, 대학관계자 및 동료지도자들 과의 관계 안에서 발원하고 있었다. 이는 지도자의 처우 개선이 이뤄질지라도 이해당사자들의 욕구에 대한 개선 책이 강구되지 않는다면, 이들의 욕구(inter-needs)는 다른 형태의 압력으로 변질되어 지도자의 일탈적 대응을 재발시킬 수 있음을 시사한다. 따라서 지도자 개인의 '역 할갈등'을 이해당사자들의 '역할기대'와 연결지어 바라보 는 총체적 관점(Jones, 2004)이 활성화될 필요가 있다.

둘째, 학교장과 감독교사들을 대상으로 한 '과정중심 인센티브제'가 도입되어야 한다. 보상체계의 감축은 학교 장의 운동부 운영동기 저하와 감독교사의 보직기피 현상 을 야기하였다. 학교운동부의 우수운영에 관한 과정중심 인센티브제의 도입은 학교장 및 감독교사에게 동기를 제 공함으로써 '운동부 해체'와 '보직 기피'현상을 완화할 수 있다. 운영의 과정에서 가치를 모색토록 장려하는 방식은 인권 친화적 운동부 시스템 정착 및 지속의 동력이 될 수 있다.

셋째, 학교운동부지도자가 인성교육자로서의 역할을 지속하기 위해 규범적, 모범적, 이상적 역할권고와 함께 그것의 위험요인과 보호장치에 대한 논의가 이뤄져야 한 다. 일례로 스포츠혁신위원회가 추구하는 혁신의 방향과 상통하는 돌봄(caring) 담론의 궤적을 추적해볼 수 있다. 돌봄 담론의 요점은 엘리트 코치가 운동지도와 더불어 선 수의 폭넓은 사회기술 함양에 시간을 할애하고, 인권과 안전을 존중하며, 이후의 삶을 준비시키는 역할에 전념해 야 한다는 것이다(Cronin et al., 2019; Fisher et al., 2017; Knust \& Fisher, 2015). 이처럼 돌봄을 코치의 주요역할 혹은 의무(duty)로 설정해야 한다는 논의 (Annerstedt \& Lindgren, 2014; Cronin \& Armour, 
2017; 2019; Grant, Piper \& Taylor, 2013)와 함께, 돌봄의 실천이 현실의 장면에서 코치(혹은 교수자)에게 '위험할 수 있음'을 경계하는 논의(Johnson, 2000; Jones, Bailey \& Santos, 2013; McCuaig, 2012; Piper \& Smith, 2003; Piper, \& Stronach, 2008)가 다각적으로 이뤄지고 있다. 하지만, 국내의 경우 인성교 육자로의 역할수행이 수반하는 위험요인과 보호장치에 대한 논의는 희소하다. 이러한 논의의 보강은 잠재적 '가 해자로서의 지도자'를 규제하는 데에 집중된 제도가 아 닌, 잠정적 '피해자로서의 지도자'를 보호하는 균형 잡힌 제도로의 보완에 근거를 제공할 것이다.

넷째, 지도자들이 인성교육자로서의 역할을 온전히 수 행하기 위해 편협한 '권력인식'과 '대안적 페다고지'의 부 재를 해결해야 한다. 본 연구의 참여자들은 규제중심의 정책과 소송의 위험에 경직되어있었고, 요즘 선수들의 권 리악용에 취약한 패닉상태(Piper \& Stronach, 2008, p. 38)에 빠져있었다. 이처럼 코치는 다방면에서 권력의 조 정을 요구받기에(Cronin \& Armour, 2019, p. 7), 권력 의 다양한 유형 4$)$ 을 이해하고 적절히 활용함으로써, 선수 와의 관계적 균형을 효과적으로 유지해야 한다(Pietzsch \& Watson, 2016; Purdy, 2018, p. 60-64). 따라서 이 와 같은 논의의 보충은 권력을 축출하는데 치중된 연수가 아닌, 권력의 유형을 이해하고 그것을 안전 범위에서 녹 여낼 역량함양을 위한 교육기회를 확보하는데 기여할 수 있을 것이다.

다섯째, 정부의 '제도 간' 불협화음은 조율되어야 한다. 지도자들이 학업의 필요성을 유보하고 학생선수를 운동 에 몰두시키는 노선을 고수하는 연유는 체육특기자제도 가 이들로 하여금 반-학업적인 방향을 택하도록 종용하 기 때문이었다(Myung, 2017; Tak, 2018). 물론 스포츠 혁신위원회에서 권고한 입시체제의 변혁은 희망적이다. 하지만, 이와 함께 제 3 기관의 관리·감독으로 입시제도의 절차적 공정성이 확보되지 않는다면, 또 다른 형태의 부 정입시가 재발할 공산이 크다. 대입과정의 자기감시체제 는 관련자들의 이해(interest) 일치에 따른 공모, 동조,

4) Pietzsch \& Watson(2016)는 French \& Raven의 사회적 권력(Social power)에 기반하여 합법적 권력, 전문적 권력, 정보적 권력, 강압적 권력, 보상적 권력, 준거적 권력을 제시 한다.
묵인의 가능성을 허용하기 때문이다.

여섯째, 정부의 '제도 내' 불협화음은 조율되어야 한다. 지도자들은 학습권 보장제의 취지에 긍정적으로 반응했 지만(Lee \& You, 2012), 지도상의 문제점, 훈련시간의 부족, 성적에 대한 압박 등, 운영상의 제한요소에 우려를 표하기도 했다(Yeo et al., 2013). 따라서 정부 및 관련 기관은 학습권 보장제를 권고하는 노력과 함께, 시·도 간에 제도 및 정책이 동일하게 적용되지 않는 문제를 예방할 실질적 관리장치의 마련에도 관심을 기울일 필요가 있다.

\section{참고문헌}

An, J. C. (2019). Human Rights and Human Rights Sensitivity in Sports. Journal of the Korean Society for the Philosophy of Sport, Dance \& Martial Arts. 27(4), 59-71.

Annerstedt, C., \& Lindgren, E. C. (2014). Caring as an important foundation in coaching for social substantiality: a case study of a successful Swedish coach inhigh-performance sport. Reflective Practice, 15(1), 27-39.

Barnett, N. P., Smoll, F. L., \& Smith, R. E. (1992). Effects of enhancing coach-athlete relationships on youth sport attrition. The sport psychologist, 6(2), 111-127.

Bing, W. C., \& Jang, Y. S. (2010). The Study on Rationalization of Athletics Team Coach's Unethical Behavior. Korean Journal of Sports Science 19(4), 39-46.

Busan Metropolitan of Education. (2019). School athlete club operation guide.

Choi, E. C. (2009). Developing a humanities-oriented approach to coach education. Korean Journal of Sport Pedagogy 16(1), 119-143.

Choi, E. C. (2012). Whole athlete development and humanities-oriented sports coaching: reconceptualizing sports coaching as a pedagogical endeavor. Korean Journal of Sport Pedagogy 19(2), 1-25.

Choi, Y. J. (2019). Coach of school athlete's Voice of the field for betterment of labor condition. Journal of Korea Society of Sport Policy. 17(1), 61-73.

Chungc-heong-namdo office of education. (2020). School Athlete Club's Operation guidebook.

Coulter, T., Gilchrist, M., Mallett, C., \& Carey, A. (2016). Abraham 
Maslow: Hierarchy of coach and athlete needs. In Nelson, L, Groom, R, \& Potrac, P. (Eds), Learning in Sports Coaching (pp. 63-74). NY: Routledge.

Cronin, C., \& Armour, K. M. (2017). 'Being'in the coaching world: new insights on youth performance coaching from an interpretative phenomenological approach. Sport, Education and Society, 22(8), 919-931.

Cronin, C., \& Armour, K. M. (2019). Care in sport coaching: pedagogical cases. NY: Routledge.

Cronin, C., Walsh, B., Quayle, L., Whittaker, E., \& Whitehead, A. (2019). Carefully supporting autonomy - learning coaching lessons and advancing theory from women's netball in England. Sports Coaching Review, 8(2), 149-171.

Cushion, C. J., Armour, K. M., \& Jones, R. L. (2003). Coach education and continuing professional development: Experience and learning to coach. Quest, 55(3), 215-230.

Entman, R. M. (1993). Framing: Toward clarification of a fractured paradigm. Journal of communication, 43(4), 51-58.

Fisher, L. A., Bejar, M. P., Larsen, L. K., Fynes, J. M., \& Gearity, B. T. (2017). Caring in US National Collegiate Athletic Association Division I sport: the perspectives of 18 female and male head coaches. International Journal of Sports Science \& Coaching, 12(1), 75-91.

Garratt, D., Piper, H., \& Taylor, B. (2013). 'Safeguarding'sports coaching: Foucault, genealogy and critique. Sport, education and society, 18(5), 615-629.

Gitlow, H., \& McNary, L. (2006). Creating Win-Win Solutions for Team Conflicts. Journal for Quality \& Participation, 29(3), 20-26.

Han, S. B. (2014). The alienation of student-athletes from Marx's Perspective. The Korean Journal of Physical Education. 53(2), 79-91.

Hjälm, S., Kenttä, G., Hassmenan, P., \& Gustafsson, H. (2007). Burnout Among Elite Soccer Coaches. Journal of Sport Behavior, 30(4), 415-427.

Hong, D. K. \& Ryou, T. H. (2007). Student Athletes in teams of humans rights: an educational discourse. Korean Journal of Sport Pedagogy 14(4), 131-154.

Hwang, S. H. (2017). A Study on the Deviant Over conformity Phenomenon of Secondary School Student Athlete. The Korean Journal of Physical Education. 56(6), 117-129.

Im, Y. S., Ryu, T. H., Shin. J. Y., \& Lee. G. I. (2017). Exploration on the process that drop-out student athletes have been adapting from an athlete to a student after dropped out. Journal of Physical Education. 13(2), 1-13.

James, L. T, Bryan, D. J., \& Frank, R. B., (2019). PunctuatedEquilibrium Theory: Explaining Stability and Change in Public Policy making. in Sabatier, P. (Eds), Theories of the policy process (pp. 155-188). NY: Routledge.

Jang, Y. J., \& Zae, S. Z. (2019). A Narrative Inquiry on Non P.E. Teachers' Role Experience in the Head Teacher of a Baseball Team -Based on The Case of A Korean Language Teacher in Middle School. Journal of Learner-Centered Curriculum and Instruction. 19(5), 695-716.

Jeon, Y. H., \& Shin, K. C. (2016). A Qualitative Case Study of the Occupational Lives of Coaches Who Work in the Elementary School Athletic Club. The Korean Journal of Elementary Physical Education, 21(4), 117-130.

Jeong, D. E. \& Lee, K. S. (2019). A Consensual Qualitative Research on the Awareness of Coaching Expertise of Elementary School Women's Table Tennis Leaders. Korean Journal of Convergence Science. 8(4), 1-39.

Johnson, R. (2000) Hands off! The disappearance of touch in the care of children. NY: Peter Lang.

Jones, R. (2004). Coach's roles. in Jones, R., Armour, K. M., \& Potrac, P. (Eds.), Sports coaching cultures: From practice to theory (pp. 116-134). NY: Routledge.

Jones, R. L., \& Wallace, M. (2006). The coach as 'orchestrator': More realistically managing the complex coaching context. in R. L. Jones (Eds), The sports coach as educator (pp. 69-82). London: Routledge.

Jones, R. L., Armour, K. M., \& Potrac, P. (2002). Understanding the coaching process: A framework for social analysis. Quest, 54(1), 34-48.

Jones, R. L., Bailey, J., \& Santos, S. (2013). Coaching, caring and the politics of touch: A visual exploration. Sport, education and society, 18(5), 648-662.

Joong-ang ilbo. (2020.01.08.). 'Ice Hockey Entrance Corruption' Two professors of Yonsei University were arrested...“they plead guilty"

JTBC News. (2018.11.20.) Korea University is also suspicious of the pre-arrangement of student-athlete ... the list of a successful candidate pre-released was concord.

Jung, B. H., \& Kim. H. Y. (2017). A Study on School Violence Experienced by Male Students of High School Athletic Team. Korean Journal of Sports Science 26(1), 737-747. 
Jung, J. Y. \& Choi, Y. L. (2010). The Negative Aspect of Social Capital on School Athletics: A Case Study of KBS Investigative Report SSAM “the Mafia of Court”. Korean journal of physical education. 49(5), 49-59.

Jung, K. H., Won, Y. S., \& Lee, E. (2018). Ethnography on Student-Athletes' Experiences of Physical Abuse. Journal of the Korean society for Wellness 13(4), 175-186.

Jung, Y. W. \& Oh, H. T. (2015). Astudy on the conceptualization of human rights in sport. Journal of Korean Society for Sport Anthropology. 10(1), 27-46.

Kang, G. M. (2018). Study on the Prevention of Sports Sexual Violence in School Sports Field. The Korean Journal of Sport. 16(2), 415-425.

Kay, A. (2005). A critique of the use of path dependency in policy studies. Public administration, 83(3), 553-571.

KBS news. (2018.07.15.). "Coach beat student", principal is also liable for compensation.

Kim, B. J., \& Kim, J. H. (2019). Sports Human Rights Blind Spot: Taekwondo Player Human Rights Problems and Social Responsibility. Journal of the Korean Society for the Philosophy of Sport, Dance \& Martial Arts, 27(2), 35-44.

Kim, D. H. (2011). The process of adjustment to the school Lives from a normal student to a student athlete. Korean Journal of Sport Pedagogy 18(1), 71-90

Kim, E. J. (2012). A case study on the management of elementary school sports clubs. Unpublished master thesis. Chungju National University.

Kim, J. H. (2011). Revisiting on Athlete-Centered Coaching of Coaches. Journal of Coaching Development 13(1), 49-55.

Kim, J. H., Kim, S. H., Cho, M. H., \& Choi, H., J. (2007). AReview of Coach Education for Professional Practitioners. Journal of Coaching Development 9(3), 3-21.

Kim, J. S. (2015). A 3 Year-Longitudinal Study on the Changes of Student-athletes in Educational Rights Guarantee Policy. Korean Journal of Sports Science 24(3), 1059-1069.

Kim, M. Y., \& Cho, M. H. (2004). A Study on the Dilemmas of Low Achievement Athletes at a Urban High School. Korean Association of Sport Pedagogy. 11(2), 177-191.

Kim, S. H. (2009). What makes good coach?: competence of a desirable coach. The Korean Journal of Physical Education, 48(2), 183-194.

Kim, S. J., \& Park, I. S. (2017). The Life of a School Sports Coach Viewed from Spinoza's Ideas. Korean journal of physical education. 56(6). 227-239.

Kim, S. K. (2009). On the human right of student sports player and the guaranteeing of their right to education. The Korean Association of Sports Law. 12(1), 11-36.

Kim, Y. R. (2010). The analysis of news framing on human right of student athletes. Korean Society for the Sociology of Sport. 23(3), 37-53.

Knust, S. K., \& Fisher, L. A. (2015). NCAADivision I female head coaches' experiences of exemplary care within coaching. International Sport Coaching Journal, 2(2), 94-107.

Korea University Sport Federation. (2020). University Sport Operation regulation.

Lee, E, M. \& Cho, M.. H. (2018). The Development of a Swimming Coachs Humanistic Coaching Expertise: through Self-Study. Journal of Coaching Development 20(1), 12-26.

Lee, H. G., \& Lee, W. H. (2013). 4th grade in the High School, The story of flunked student-athlete: the reason, experience and plan. The Korean Journal of Physical Education. 52(1), 49-58.

Lee, J. J. (2015). The Study on the difficulties about School Athletic Instructor' job performance. Unpublished master thesis. Sognag Graduate School of Education. Seoul.

Lee, J. S. \& Im, H. J. (2019). Perception Types and Characteristics of Student Athletes on Physical Punishment. Journal of Coaching Development 21(2), 24-32.

Lee, Y. G., \& You, J, A. (2012). The Assessment of Implementation and Output on Minimum Academic Achievement Policy from School Sport Coaches' Perception. The Korean Journal of Elementary Physical Education. 18(3), 181-191.

Lee, D. H. (2008). Astudy on parental culture: Focused on parents' educational support activities for children. Korean Journal of Sociology of Education. 18(3), 135-165.

Lee, J. M. (1989). Causes, results and countermeasures of job stress. Seoul: Sungwonsa.

Lim, H. E., \& Yoon, K. J. (2019). How Do Coaches Practice Character Education in Secondary School Athlete Clubs?: a Case Study. Korean Journal of Sport Pedagogy 26(3), 73-88.

Lim, S. M. (2014). Critical consideration over the recognition of school sports team's coaches on the operation of school sports teams. Korean Journal of Sports Science. 23(5), 195-208.

McCuaig, L. A. (2012). Dangerous carers: Pastoral power and the caring teacher of contemporary Australian schooling. Educational Philosophy and Theory, 44(8), 862-877.

Ministry of Culture, Sports and Tourism. (2019a). sports 
innovation committee's first Recommendation.

Ministry of Culture, Sports and Tourism. (2019b). sports innovation committee's second Recommendation.

Ministry of Culture, Sports and Tourism. (2019c). sports innovation committee's third Recommendation.

Myung, W. S. (2017). The socio-cultural background and the current issues of camp training system in school sport. Korean Journal of Sport Science. 28(3), 592-607.

National Human Right Commission of The Republic of Korea. (2019.11.07). The complete enumeration on Human Rights condition in Sports area.

Patton, M. Q. (2015). Qualitative evaluation and research methods(4th ed). CA: Sage.

Pietzsch, F., \& Watson, H. (2015). Athlete-coach relationship. a case study from woman's professional tennis in Wallis, J., \& Lambert, J. (Eds.), Becoming a Sports Coach (pp. 122-136). NY: Routledge.

Piper, H., \& Smith, H. (2003). ‘Touch'in educational and child care settings: dilemmas and responses. British educational research journal, 29(6), 879-894.

Piper, H., \& Stronach, I. (2008). Don't touch!: The educational story of a panic. London: Routledge.

Porter, L. W., \& Steers, R. M. (1973). Organizational, work, and personal factors in employee turnover and absenteeism. Psychological bulletin, 80(2), 151-176.

Purdy, L. (2018). Sports coaching: The basics. NY: Routledge.

Seong, C, H., Hong, J. H., \& Choi, E. K. (2004). Components and Obstacles of positive coaching in school-based coaching. Korean Journal of Sport Psychology. 15(4), 151-168.

Seoul metropolitan of education. (2017). School Athlete Club's Manual.

Seoul metropolitan of education. (2018). School Athlete Club's Manual.

Seoul metropolitan of education. (2019). School Athlete Club's Manual.

Seoul metropolitan of education. (2020). School Athlete Club's
Operation workbook

Song, M. S., \& Lee, J. H. (2015). Performance Role Task for Increase of Sport Human Rights in School Athlete Coach. Journal of Korean Society of Sport Policy, 13(1), 29-50.

Song, Y. K., Eom, H. J., \& Shin, M, j. (2010). Understanding for Learning experiences on athlete student: with an emphasis on the right to learn. Korean Journal of Sport Pedagogy. 17(1), 89-109.

Song, Y. K., Lee, C., \& Kim, B. Y. (2013). Between calm and passion: awareness on the education activities for athlete students. Journal of Sport and Leisure Studies. 54(1), 97-113.

Stafford, I. (2011). Coaching children in sport. NY: Taylor \& Francis.

Sun, H. G. (2019). A Study on the Lowest Education and E-School Recognition of Badminton Students in High School. The Journal of Korean Alliance of Martial Arts. 21(3). 111-128.

Tak, M. H. (2018). Three conceptual tools for studying sports-related social/policy institutions: cost, path and grains. Korean Society for the Sociology of Sport. 31(1), 171-196.

Yeo, J. K., Lee, C. S., Yi, J. W., \& Ku, Geon. Mo. (2013). Minimum Academic achievement to Recognize of High School Athletic sport. Korean Society for the Sociology of Sport 26(1), 185-205.

Yonhap news. (2019. 06.18). sports innovation without opinions on the field, sportsmen feel like they are being ignored.

Yonhap news. (2019. 10.31). The school athlete team shakes at '52 hours a week service system...' we couldn't even participate in the competition.

Yoon, I. A. (2018). The Coaching Strategies of High School Soccer Coaches in Dealing with the Changing Social Phenomenons of School Sports. Journal of the Korean society for Wellness 13(3), 499-513.

Yu, T. H. (2005). The problem and the prospective of korea school athletic sport. Korean Journal of Sport Pedagogy 12(2), 91-108. 


\title{
학교운동부지도자의 직업적 고충과 대응에 관한 연구
}

\author{
유주영 ${ }^{1}$, 이옥선 ${ }^{2}$ \\ ${ }^{1}$ 서울대학교 석사 \\ ${ }^{2}$ 서울대학교 교수
}

〔목적〕 본 연구의 목적은 학교운동부지도자의 직업적 고충을 중층(관계-제도)의 관점에서 이해하고, 대응 의 성질을 분석함으로써, 향후 인권·친화적 학교운동부 시스템 정착을 위한 시사점을 제공하는 데 있다. 〔방 법] 이를 위해 초, 중, 고 학교운동부지도자 $(\mathrm{n}=5$, 평균경력 19.2년)를 참여자로 선정하였다. 연구자료는 반구조화된 면담으로 수집되었다. 수집된 자료는 귀납적으로 분석되었다(Patton, 2015).〔결과〕첫째, 참여자 들은 학교운동부 조직 내외의 이해당사자들의 역할기대에 지쳐있었다. 둘째, 운동부 관련 제도 및 정책인 학습 권 보장제, 주 52 시간 근로제, 인권 보장제는 지도자들의 공식적, 비공식적 역할수행에 어려움을 가중시켰다. 셋째, 이해당사자들의 관계적 요구와 정부기관의 제도적 이상의 불협화음은 참여자들로 하여금 반제도적, 비 윤리적, 비교육적 자충수를 택하도록 종용하였다. (결론) 연구결과를 바탕으로 '인권 친화적 학교운동부 문화 의 토착화를 위해 정부, 학계, 사회전반이 운동부지도자를 '혁신의 대상'으로 설정하기보다, 함께 문제를 풀어 갈 ‘혁신의 주체’로 재인식해야 함을 제언하였다. 이러한 결론은 이해당사자들의 요구와 관련 정책의 간극을 좁히는데 유효한 시사점을 제공할 것으로 기대된다.

주요어: 학교운동부 시스템, 지도자의 직업적 고충, 대응전략 